\title{
Rancang Bangun Sistem Pengendali Suhu Ruangan Menggunakan Fuzzy LOGIC
}

\author{
${ }^{1}$ Iksal, ${ }^{2}$ Saefudin , ${ }^{3}$ Ilham Aswad \\ ${ }^{1}$ Jurusan Sistem Komputer Universitas Serang Raya \\ 2,3 Jurusan Teknik Informatika Universitas Serang raya \\ e-mail: ${ }^{1}$ iksal_r@yahoo.com, ${ }^{2}$ saefudin12@gmail.com, ${ }^{3}$ ilhamaswad@ymail.com
}

\begin{abstract}
Abstrak. Semakin banyak jumlah orang di dalam ruangan maka semakin besar daya AC yang dibutuhkan karena pada dasarnya tubuh manusia mengeluarkan kalori yang cukup tinggi, begitu juga dengan luas ruangan.Sementara suhu yang dikeluarkan pendingin ruangan (AC) terkadang terasa cukup, terlalu sejuk, kurang sejuk dan lain sebagainya di kulit manusia. Dengan Inferensi Fuzzy dapat ditentukan suhu optimal yang akan dikeluarkan oleh pendingin ruangan pada ruang tertutup berdasarkan jumlah orang dalam ruangan, luas ruangan (m2), jumlah pendingin ruangan, dan spesifikasi besaran daya kompresor AC yang digunakan.Penentuan suhu yang optimal dalam ruangan sangat penting karena suhu yang optimal akan memberi pengaruh positif bagi kesehatan dan penghematan energi.Penelitian ini berhasil menemukan suhu optimal suatu ruangan dengan menggunakan metoda Inferensi Fuzzy.
\end{abstract}

Kata kunci: Suhu Optimal, Pendingin Ruangan, FIS-Tsukamoto, Fuzzy Logic.

\section{Pendahuluan}

Kebutuhan kenyamanan dalam sebuah ruangan pada abad ini seperti sebuah kebutuhan pokok yang mendasar. Akan tetapi semakin banyak jumlah orang di dalam ruangan maka semakin besar daya AC yang dibutuhkan, karena pada dasarnya manusia yang mengisi suatu ruangan mengeluarkan suhu tubuh yang cukup tinggi, begitu juga dengan luas/ukuran ruangan. Suhu yang dikeluarkan pendingin ruangan (AC) terkadang terasa cukup, terlalu sejuk, kurang sejuk dan lain sebagainya di kulit manusia.

Di era perkembangan teknologi yang semakin maju saat ini,banyak solusi yang dapat memecahkan permasalahan manusia. Permasalahan yang timbul akibat keterbatasan manusia ataupun dari faktor lain, kini sedikit demi sedikit sudah dapat diatasi. Salah satu solusi yang dapat memecahkan permasalahan manusia yaitu dengan menggunakan sistem kendali berbasis komputer. Dengan menggunakan sistem kendali berbasis komputer, diharapkan dapat membantu dan meringankan pekerjaan manusia.

Pengaturan suhu AC yang kurang optimal pada suatu ruangan disamping akan berdampak negatif terhadap kesehatan manusia juga menyebabkan pemborosan energi.

Salah satu cara untuk mendapatkan suhu yang optimal adalah membuat alat yang dapat mengendalikan suhu ruangan berdasarkan jumlah manusia dan luas ruangan.Namun sebelum proses pembuatan suatu alat maka perlu dilakukan simulasi yang berbasis komputerisasi guna meminimalisir terjadi kesalahan sistem dan sebagai acuan pembuatan alat.Sementara salah satu metoda optimalisasi suhu ruangan adalah metoda Inferensi Fuzzy.Dengan menggunakan inferensi fuzzy ini dapat ditentukan suhu optimal yang akan dikeluarkan oleh pendingin ruangan pada ruang tertutup berdasarkan jumlah orang, luas ruangan,jumlah pendingin ruangan,dan spesifikasi besaran daya kompresor AC yang digunakan. 
Metode fuzzy logic ini mempunyai beberapa kelebihan salah satunya adalah penggunaannya yang mudah dan dalam proses menghasilkan keputusan lebih sesuai dengan kondisi manusia. Fuzzy logic memodelkan perasaan atau intuisi dengan cara merubah nilai crisp menjadi nilai lingustik dengan fuzzification dan kemudian memasukannya ke dalam rule yang dibuat berdasarkan knowledge. Kelebihan yang kedua adalah Fuzzy logic cocok digunakan pada sebagian besar permasalahan yang terjadi di dunia nyata. Permasalahan di dunia nyata kebanyakan bukan biner dan bersifat non linier sehingga fuzzy logic cocok digunakan karena menggunakan nilai lingustik yang tidak linier. Fuzzy logic dapat mengekspresikan konsep yang sulit untuk dirumuskan, seperti misalnya "suhu ruangan yang nyaman". Pemakaian fungsi keanggotaan memungkinkan fuzzy logic untuk melakukan observasi obyektif terhadap nilai-nilai yang bersifat subyektif. Selanjutnya fungsi keanggotaan ini dapat dikombinasikan untuk membuat pengungkapan konsep yang lebih jelas.

Berdasarkan penjelasan di atas maka pada penelitian ini akan dibuat simulasi sistem pengatur suhu ruangan (Air Conditioning) untuk menentukan suhu optimal berbasis logika fuzzy.

\section{Metode Fuzzy Tsukamoto}

Sistem Inferensi Fuzzy merupakan suatu kerangka komputasi yang didasarkan pada teori himpunan fuzzy, aturan fuzzy berbentuk IF-THEN, dan penalaran fuzzy. Secara garis besar, diagram blok proses inferensi fuzzy sebagai berikut:

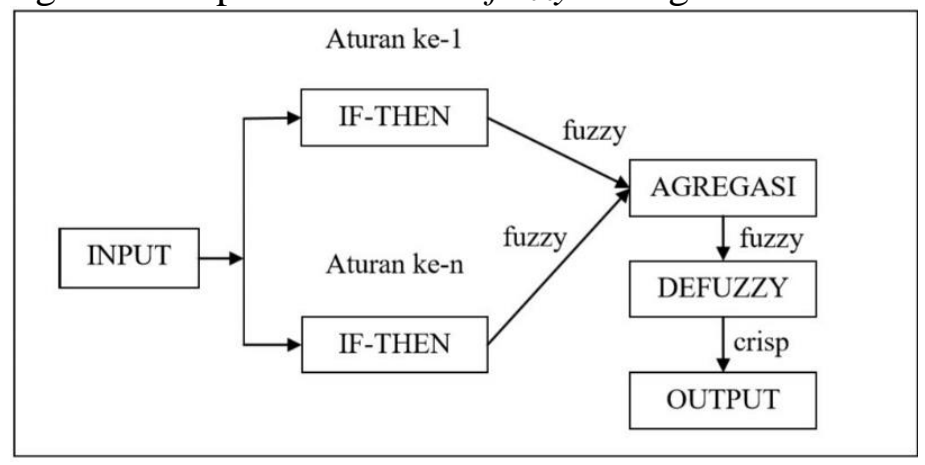

\section{Gambar 1 : Diagram Blok Sistem Inferensi Fuzzy Tsukamoto}

Sistem inferensi fuzzy menerima input crisp. Input ini kemudian dikirim ke basis pengetahuan yang berisi $\mathrm{n}$ aturan fuzzy dalam bentuk IF-THEN. Fire strength akan dicari pada setiap aturan. Apabila jumlah aturan lebih dari satu, maka akan dilakukan agregasi dari semua aturan. Selanjutnya, pada hasil agregasi akan dilakukan defuzzyfikasi untuk mendapatkan nilai crisp sebagai output sistem.

Pada dasarnya, metode Tsukamoto mengaplikasikan penalaran monoton pada setiap aturannya. Kalau pada penalaran monoton, sistem hanya memiliki satu aturan, pada metode Tsukamoto, sistem terdiri atas beberapa aturan. Karena menggunakan konsep dasar penalaran monoton, pada metode Tsukamoto, setiap konsekuen pada aturan yang berbentuk IF-THEN harus direpresentasikan dengan suatu himpunan fuzzy dengan fungsi keanggotaan yang monoton. Output hasil inferensi dari tiap-tiap aturan diberikan secara tegas (crisp) bedasarkan $\alpha$-predikat (fire strength). Proses agregasi antar aturan dilakukan, dan hasil akhirnya diperoleh dengan menggunakan defuzzyfikasi dengan konsep rata-rata terbobot. 
Misalkan ada variabel input, yaitu x dan y, serta satu variabel output yaitu $\mathrm{z}$. juga, yaitu B1 dan B2, sedangkan variabel output $\mathrm{Z}$ terbagi atas 2 himpunan yaitu $\mathrm{C} 1$ dan $\mathrm{C} 2$. Tentu saja himpunan $\mathrm{C} 1$ dan $\mathrm{C} 2$ harus merupakan himpunan yang bersifat monoton. Diberikan 2 aturan sebagai berikut :

IF $\mathrm{x}$ is $\mathrm{A} 1$ and $\mathrm{y}$ is $\mathrm{B} 2$ THEN $\mathrm{z}$ is $\mathrm{C} 1$

IF $x$ is $A 2$ and $y$ is $B 2$ THEN $z$ is $C 1$

\section{Metode Penelitian}

Analisa Variabel yang diasumsikan mempengaruhi suhu optimal suatu ruangan dengan menggunakan logika fuzzy adalah sebagai berikut:

a) Jumlah Orang

Tabel 1: Keanggotaan dan Domain untuk Variabel Jumlah Orang

\begin{tabular}{|l|l|}
\hline \multicolumn{1}{|c|}{ Klasifikasi } & \multicolumn{1}{c|}{ Jumlah Orang } \\
\hline Sedikit & $\leq 10$ \\
\hline Sedang & 20 \\
\hline Banyak & $\geq 30$ \\
\hline
\end{tabular}

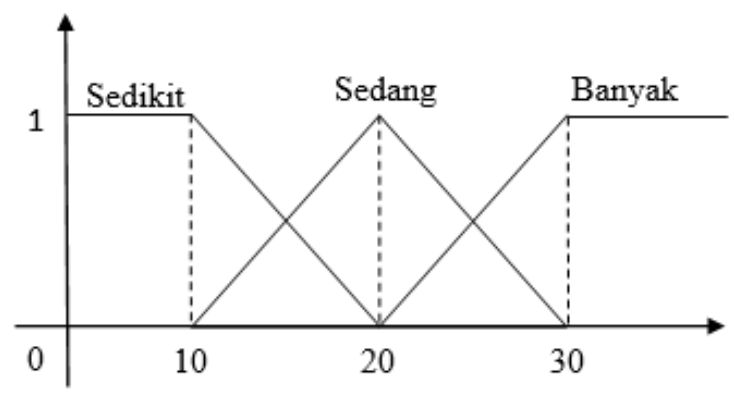

Gambar 2: Grafik Jumlah Orang

b) Jumlah AC

Tabel 2: Keanggotaan dan Domain untuk Variabel Jumlah AC

\begin{tabular}{|l|l|}
\hline \multicolumn{1}{|c|}{ Klasifikasi } & \multicolumn{1}{c|}{ Jumlah Orang } \\
\hline Sedikit & $\leq 1$ \\
\hline Sedang & 2 \\
\hline Banyak & $\geq 4$ \\
\hline
\end{tabular}

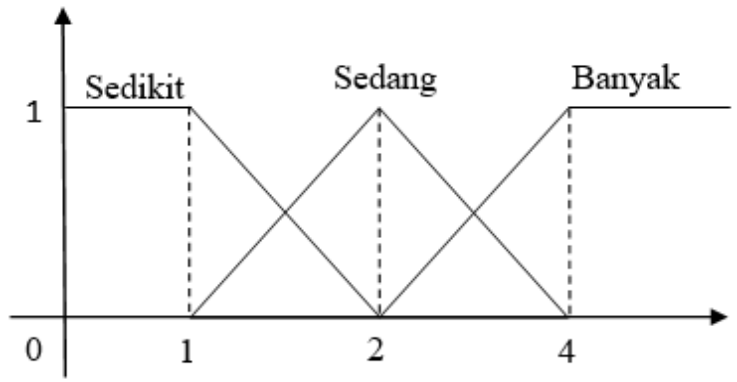

Gambar 3: Grafik Jumlah AC 
c) Volume Ruangan

Tabel 3: Keanggotaan dan Domain untuk Variabel Volume Ruangan

\begin{tabular}{|l|l|}
\hline \multicolumn{1}{|c|}{ Klasifikasi } & \multicolumn{1}{c|}{ Jumlah Orang } \\
\hline Sempit & $\leq 20$ \\
\hline Sedang & 60 \\
\hline Besar & $\geq 100$ \\
\hline
\end{tabular}

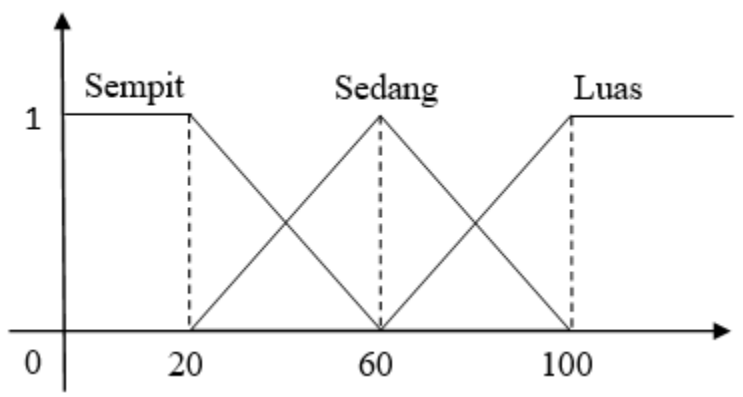

Gambar 4: Grafik Luas Ruangan

d) Suhu Eksternal

Tabel 4: Keanggotaan dan Domain untuk Suhu Eksternal

\begin{tabular}{|l|l|}
\hline \multicolumn{1}{|c|}{ Klasifikasi } & \multicolumn{1}{c|}{ Jumlah Orang } \\
\hline Kecil & $\leq 10$ \\
\hline Sedang & 20 \\
\hline Tinggi & $\geq 30$ \\
\hline
\end{tabular}

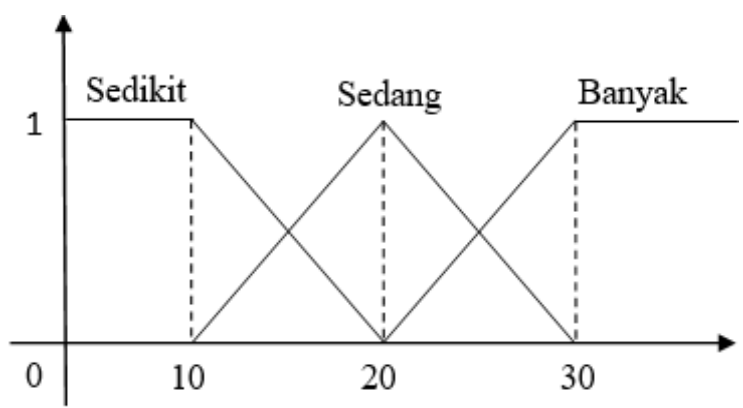

Gambar 5: Gambar Grafik Suhu Eksternal

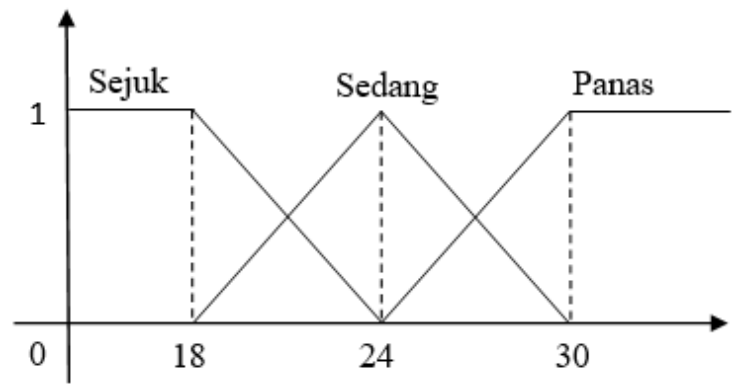

Gambar 6: Grafik Suhu Optimum 


\section{Hasil dan Pembahasan}

\section{SIMULASI AC}

Halaman inidi. Fuzzy Logic

Operator dapat menentukan suhu optimal dengan memasukan jumlah orang, jumlah ac, luas uangan, dan suhu eksternal untuk mendapatkan hasil suhu yang optima.

\begin{tabular}{|c|c|c|}
\hline $\begin{array}{r}\text { Jumlah Orang Terkecil } \\
\vdots \\
\vdots\end{array}$ & $\begin{array}{r}\text { Jumlah Orang Sedang } \\
\vdots\end{array}$ & Jumlah Orang Terbanyak \\
\hline Jumlah AC Sedikit & Jumlah AC Sedang & $\begin{array}{l}\text { Jumlah AC Banyak } \\
\vdots \\
\vdots\end{array}$ \\
\hline $\begin{array}{c}\text { Volume Ruangan Sempit } \\
:\end{array}$ & Volume Ruangan Sedang & $\begin{array}{c}\text { Volume Ruangan Besar } \\
\vdots\end{array}$ \\
\hline $\begin{array}{l}\text { Suhu Eksternal Kecil } \\
\begin{array}{|r|} \\
\end{array}\end{array}$ & $\begin{array}{r}\text { Suhu Eksternal Sedang } \\
\vdots\end{array}$ & Suhu Eksternal Tinggi \\
\hline Jumlah Orang & Jumlah AC & \\
\hline Volume Ruangan & Suhu Eksternal & \\
\hline
\end{tabular}

MULAI RESET CANCEL

Gambar 7: Aplikasi Simulasi Penerapan Inferensi Fuzzy untuk Menentukan Suhu Ruangan pada Pendingin Ruangan (AC)

Berikut adalah output dari proses yang dilakukan:

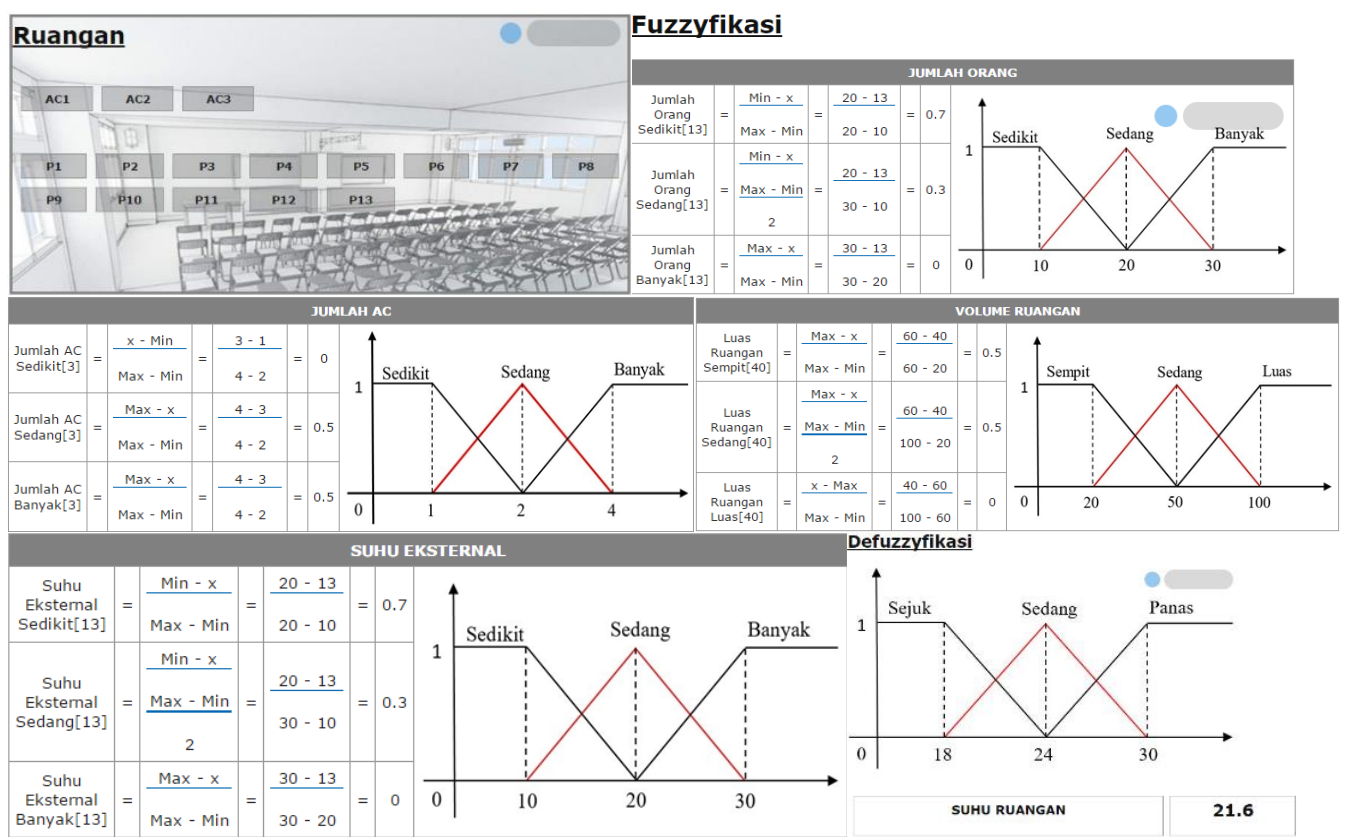

Gambar 8: Output Suhu Optimal dari Aplikasi

Berikut adalah pembahasan dari input proses dan output yang dijalankan dari aplikasi:

Input sistem berupa variabel fuzzy:

Jumlah Orang

Jumlah AC

$: 13\left[\right.$ dalam $\left.\mathrm{m}^{2}\right]$

Suhu Eksternal

$: 3$

: 13 [dalam ukuran Celcius] 


\section{2 | Iksal, et al}

\section{Kesimpulan}

Berdasarkan hasil pembahasan yang disajikan sebelumnya dapat ditarik kesimpulan sebagai berikut:

1. Simulasi sistem pengendali suhu ruangan menggunakan fuzzy logic berhasil dibuat dengan cara membuat derajat keanggotaan agar dapat menentukan temperatur suhu optimal.

2. Dengan menggunakan metode fuzzy logic maka di dapat variabel jumlah orang, jumlah AC, luas ruangan, dan spesifikasi AC untuk mengoptimalkan suhu AC.

3. Sistem yang dirancang dan disimulasikan lebih efektif dalam membaca klasifikasi suhu ruangan, karena dengan logika fuzzy clustering pembacaan suhu secara teori dan aplikasi bisa dilakukan.

\section{Daftar Pustaka}

Anita Desiani, Muhammad Arhami.(2006). Konsep kecerdasan Buatan. Yogyakarta : C.V Andi Offset

Argo, Bambang Dwi, dkk. (2007). Model simulasi pengendalian suhu udara pada mesin pengering cabe dengan kontrol logika fuzzy. J.Tek.Pert. Vol.5. No.(3). 156-172

Fauzana, Satria. dkk. (2010). Pengaturan Suhu Ruangan Dari AC Sentral Dengan Menerapkan Kontrol Logika Fuzzy Pada Lab. Dasar Telekomunikasi gedung D3 Lantai 3 Pens - Its. Paper Jurnal; Vol 2 No/Issue 3

H.Ogawa (1984).Labeled point pattern matching by fuzzy relaxation.Pattern Recognition,pp.569-573.

Indrabayu, dkk. (2012). Prediksi Curah Hujan Dengan Fuzzy Logic. Prosiding: Vol 6, ISBN: 978-979-127255-0-6

J.C.Bezdek and S.K.Pal.(1992).Fuzzy Model for Pattern Recognition.IEEE press,new York.

Kartina Diah KW,ST, Zulfa Noviardi. (2010). Penerapan Inferensi Fuzzy Untuk kendali Suhu Pada Pendingin Ruangan (AC). Yogyakarta: UPN "Veteran”. ISSN: 19792328

Klir, J.R., Sun, C.T., Mizutami ,E. 1997. Neuro Fuzzy and Soft Computing. Prentice Hall. London.

Kusumadewi, sri. (2003). Artificial Intelegence (Teknik dan Aplikasinya). Yogyakarta: Graha Ilmu.

L.A.Zadeh.(1988).Fuzzy logoc.IEEE Computer,pp.83-93. 